\title{
Development and Field-Testing of a Study Protocol, including a Web-Based Occupant Survey Tool, for Use in Intervention Studies of Indoor Environmental Quality
}

\author{
Mark J. Mendell, Ekaterina Eliseeva, \\ Michael Spears, William J. Fisk
}

\author{
Environmental Energy Technologies Division \\ Indoor Environment Department \\ Lawrence Berkeley National Laboratory \\ Berkeley, CA
}

June 2009

This research was supported by the U.S. General Services Administration (GSA) Public

Buildings Service (contract number PX0008425) through an interagency agreement with the U.S. Department of Energy under Contract DE-AC02-05CH11231. 


\title{
Development and Field-Testing of a Study Protocol, including a Web-Based Occupant Survey Tool, for Use in Intervention Studies of Indoor Environmental Quality Mark J. Mendell, Ekaterina Eliseeva, Michael Spears, William J. Fisk
}

\begin{abstract}
We developed and pilot-tested an overall protocol for intervention studies to evaluate the effects of indoor environmental changes in office buildings on the health symptoms and comfort of occupants. The protocol includes a web-based survey to assess the occupant's responses, as well as specific features of study design and analysis. The pilot study, carried out on two similar floors in a single building, compared two types of ventilation system filter media. With support from the building's Facilities staff, the implementation of the filter change intervention went well. While the web-based survey tool worked well also, low overall response rates (21-34\% among the three work groups included) limited our ability to evaluate the filter intervention., The total number of questionnaires returned was low even though we extended the study from eight to ten weeks. Because another simultaneous study we conducted elsewhere using the same survey had a high response rate $(>70 \%)$, we conclude that the low response here resulted from issues specific to this pilot, including unexpected restrictions by some employing agencies on communication with occupants.
\end{abstract}

In this small pilot study we were able to use formal statistical analyses for only two of six symptoms. Outdoor ozone above $58 \mathrm{ppb}$ (a common level in Sacramento and many other cities in summer) was associated with a significant $64 \%$ increase in upper respiratory symptoms. This was consistent with a prior finding from a large U.S. study Otherwise the models showed only small non-significant changes in upper respiratory symptoms and eye symptoms in the predicted directions (increases with both synthetic filters and higher ambient ozone), and found no evidence for synergy between filters and outdoor ozone in their effects on symptoms.

Based on results of the pilot, we suggest revisions in future study protocols:

- Study only buildings that can provide email addresses for all occupants in the study spaces, and accurate counts of eligible employees there.

- Develop early and direct communication with employers and employee managers, in addition to facilities staff. To increase response rates, it will be helpful to develop support within each work group from one or more influential people ("champions"). Support from employee representatives (unions) where available may also be helpful. .

- Tell participants exactly when to complete the surveys during each study period.

- Select alternate statistical approaches, such as different models or tests, to make the best use of the kind of data that the surveys produce.

The protocol should be usable for future intervention studies that assess the effects of changing the indoor environments of offices on occupant symptoms or comfort. Promising environmental factors to study, considered likely to influence the health or environmental satisfaction of occupants, in addition to reducing entry of outdoor pollutants such as ozone into indoor air, include ventilation rates, cleaning practices, and other aspects of the operation or maintenance of buildings. Estimates that we provide here on the frequencies of symptoms will also help in planning the necessary sizes of future studies. 


\section{Background}

We still have large gaps in our knowledge about the influence of various environmental factors on human health and comfort in indoor work environments such as offices. The ability to study the effects of environmental factors in buildings would be substantially improved with the availability of field-tested tools for conducting occupant surveys that were convenient, paperfree, and designed specifically for rigorous environmental intervention studies in buildings. Such research tools should collect survey data quickly and conveniently in ways that encourage high, repeated participation rates over the extended period of a crossover intervention study. The survey tools should provide real-time error checking, secure longitudinal data storage, direct data export for analysis (i.e., without manual key-entry), and simple means for contacting potential respondents regarding participation, reminders, incentives, and thanks.

We report here the results of a project in which we developed and pilot-tested a protocol for indoor environmental intervention studies in office buildings. The protocol includes implementation of a simple indoor environmental intervention in a multiple crossover design, collection of data using a web-based occupant survey, and collection of limited environmental data. This initial test supports recommendations for future improvements to the protocol. It also provides data on the distributions of the outcomes measured and the response rates to the survey over time, to help in estimating the necessary sample size for future use of the protocol.

The specific intervention used in this project compared, in two similar office spaces within one building, ventilation particle filters of two different materials. These materials, according to one previous study, may be associated with different levels of occupant symptoms, especially in the presence of moderate or higher levels of outdoor ozone (Buchanan et al. 2008]. We summarize here the findings, including results for various symptom outcomes measured, and patterns of association observed between these outcomes and various factors.

Goals

Specific goals of the study were:

- To develop and pilot-test a protocol for intervention studies in office buildings suitable for evaluating indoor environmental interventions for effects on the health and comfort of occupants..

- To develop a specific web-based survey tool for use in the pilot protocol.

- To estimate survey response rates and evaluate, as feasible, factors that could be changed to improve future response rates.

- To perform preliminary analyses of the associations between health outcomes in occupants and key environmental variables (anticipating that the pilot data would likely be too limited for complex analyses or clear findings).

- To suggest revisions for the pilot protocol and the web-based survey.

- To provide a basis, using the symptom levels and response rates in the pilot, in specifying necessary sample sizes for future application of the study protocol. 


\section{Approach}

Study preparation - protocol and survey

We developed a study protocol for conducting blinded, multiple crossover studies in two similar office spaces within a single building. In a blinded study, the subjects don't know what study condition they are experiencing at any specific time, to reduce bias in their responses. A multiple crossover design changes the conditions of interest back and forth between the study spaces multiple times during the course of the study (see Table 1). Compared to a simple twogroup before-after design, exchanging conditions between two study groups one time (single crossover) helps ensure that chance differences between the study groups themselves do not influence the conclusions about effects of the study conditions, because each group experiences each experimental condition. Exchanging the conditions multiple times (multiple crossover) helps ensure that association of outside circumstances with one study condition due to chance during a single crossover does not influence the findings, because this chance association is not likely to track systematically with the alternating conditions through multiple crossovers.

Table 1. Comparison of several experimental study designs to contrast conditions $A$ and $B$

\begin{tabular}{ccccccc}
\hline & \multicolumn{4}{c}{ Study Designs } \\
\cline { 2 - 7 } & Two-Group & \multicolumn{2}{c}{ Single } & \multicolumn{2}{c}{ Multiple } \\
& Before/After & \multicolumn{2}{c}{ Crossover } & \multicolumn{2}{c}{ Crossover } \\
\hline Study & \multicolumn{2}{c}{ Study group } & \multicolumn{2}{c}{ Study group } & \multicolumn{2}{c}{ Study group } \\
period & 1 & 2 & 1 & 2 & 1 & 2 \\
\hline 1 & A & B & A & B & A & B \\
2 & & & B & A & B & A \\
3 & & & & & A & B \\
4 & & & & & B & A \\
\hline
\end{tabular}

We developed a web-based questionnaire, based on an instrument we had previously developed using open access software (LimeSurvey - see http://www.limesurvey.org/). The overall survey protocol includes a series of repeated questionnaires, administered every two weeks. The first survey completed by each subject asks for individual background information (e.g., demographics, job and workspace information, health history). The initial and then all repeated/recurring questionnaires collect information on a number of health symptoms (severity that day at work), on various aspects of satisfaction with the indoor environment such as air quality and thermal comfort, and on a variety of secondary factors. (See Appendices 1 and 2 for the questions in the initial and the recurring questionnaire.) The finished survey tool includes secure longitudinal data tracking, data entry limits to accept only appropriate answers for each question to reduce errors, required responses to most question (even if only a response of 'no answer'), and the ability to export data for analyses using a choice of statistical software.

The survey was designed for convenient, effective administration by researchers at a remote location, using only a list of the email addresses (and optionally, first names) of all potential 
participants, supplied by the employer. The survey system generates and sends to each potential participant a sequence of emails, customizable by researchers: to describe the upcoming surveys, to notify participants during each 2-week study period during the crossover study when it is time to complete the online questionnaire, to request those who had not yet responded to complete the questionnaire, and to thank those who had completed the questionnaire. Those who explicitly decline to participate are removed from the list and receive no more emails about the survey.

Each worker willing to participate completes an electronic informed consent before completing the first survey, and accesses the survey through a personalized "web link" contained in the notification email sent during each 2 -week study period,. The link includes both a web address for the specific survey set up for that 2-week study period, as well as a personal "token" (i.d. number) for that person at that time which allows access to the correct survey at that web address. (Note that the survey system can collect data on multiple studies and multiple buildings at the same time.) The system stores, on the project's computer server, all questionnaire responses provided by each individual as data linked to the individual with that email address and the date of survey completion. Each individual receives a specific token for each study period. Respondents not completing surveys within a certain amount of time are reminded through up to two automatically generated emails, each containing the individual's web-link and token for that period. A token will not allow completion of the same survey more than once within one study period. An individual's series of tokens throughout the study are linked to the participant's email address through a data file on the server that is kept separate from the data.

After drafting the survey, we tested it among a few workers in our office and revised it as necessary.

We submitted the study protocol and the web survey to our institutional review board for Human Subjects Committee approval, made all suggested revisions, and obtained approval. (See Appendix 3 for the final approved Human Subjects Protocol. Note that within the Human Subjects Protocol in Appendix 3, the two web surveys listed as appendices 4 and 5 are not included - they are provided as Appendices 1 and 2 for this report.)

\section{Study preparation - field study}

We identified, with the assistance of federal and regional U.S. General Services Administration (GSA) staff, a suitable building and population for the pilot study. This was a federal building in a warm-climate region with substantial ambient ozone levels. The two study spaces were two floors in a large wing of the building, each said to have over 200 workers, all working in different groups within the same federal agency.

We obtained agreement to study the building and its occupants from the facility manager and the managers of the employee groups in the study spaces. The management of each group determined what access we had to the individual workers. We also made arrangements with the facility manager that their staff would provide access and support for our staff when we installed and exchanged the ventilation system filters throughout the study. All expenses for filter materials were covered by LBNL, through the support of GSA. 
We arranged for advance notification of occupants in the study areas about the study, through emails sent to the manager of each employee group by the facility manager. We also publicized, through the facility manager, advance presentations for workers in the study spaces in which we would describe the purpose and procedures of the upcoming study and encourage their participation in the surveys. We conducted three introductory presentations in large meeting rooms, using slides and answering questions.

\section{Data collection}

To test out protocol, we conducted a multiple-crossover intervention using two types of particle filters (synthetic or fiberglass media). The two study areas were the two floors in one wing of the building, each floor served by two ventilation air handling units (AHUs). We initially installed new filters on the two study floors, one kind for each floor. At the beginning of each two-week study period (on a Monday or Tuesday), we moved/exchanged the filters between floors.

Each AHU contained a rack of 20 bag filters - 15 were 2' by 2' in height and width, and five were 2' by 1', and all were 15 inches deep. The polyester/synthetic filters used were Airguard Clean-Pak, and the fiberglass filters were Airguard Venti-Pak. The two types of filters, aside from material, were very similar, with the same dimensions, 53 square feet in media area for a 2' x2' filter, MERV 13, and estimated initial pressure drop of 0.53 in $\mathrm{H}_{2} \mathrm{O}$ at $500 \mathrm{fpm}$ face velocity. We removed all prefilters for the duration of the study.

We requested questionnaire completion during the last three workdays (Wednesday - Friday) of each two-week study period, to allow an extended period for the filter material to influence symptoms among occupants. For groups of workers for whom we obtained individual e-mail addresses, we sent emails notifying them about each upcoming questionnaire period, and reminding by email (up to two times) those who had not responded. For workers whose individual email addresses we could not obtain, we provided notification emails to a single contact within their group to forward to individual workers before each questionnaire period, and to send out one general reminder during each questionnaire period. The study was originally scheduled to include four two-week periods, for a total of eight weeks, but we added one additional two-week period, resulting in a total length of 10 weeks.

In the surveys, severity of each symptom at work that day was assessed on a scale ranging from 0-10 (see Appendices 1 and 2). We analyzed four symptoms individually (eye, skin, headache, and fatigue), with integral values from 0-10. We combined six symptoms into an upper respiratory symptom index (wheezing, chest tightness, shortness of breath) and a lower respiratory symptom index (congested nose, sneezing, sore or dry throat). Index values based on the mean of the included variables thus also ranged from $0-10$, but could have fractional values. A variety of other outcomes, not analyzed here, were also assessed in the survey, including health outcomes (current respiratory illness, total absences and illness-related absences from work in the prior four weeks, and history of several diagnosed illnesses) and indoor environmental perceptions (temperature, humidity, freshness of environment, odors). In addition, a variety of personal, demographic, workspace, and job-related factors were collected. While participants were not required to answer any specific question and could stop at any time, continuing through the survey required providing for each question either a specific answer, or the response "no answer." All participants were unaware of which filter condition they were 
experiencing at any time, although they were aware that the study was comparing different kinds of commonly used ventilation system filters.

We also conducted limited environmental measurements, including real-time logging of indoor temperature and humidity using Hobo monitors (4 per study floor) and $\mathrm{CO}_{2}$ using $\mathrm{Fuji}_{\mathrm{CO}}$ meters ( 1 per study floor). Ambient ozone was estimated from U.S. EPA data (using the nearest available outdoor fixed monitoring site) for each day as the mean 8-hour concentration outdoors. Data from each completed questionnaire was linked to environmental data for the day of questionnaire completion. Before conducting analyses, we confirmed that the specific filter types had been installed on each floor as scheduled throughout the study, using dated photographs of the filters in each air handler at the beginning of each study period.

\section{Statistical Analyses}

We exported the survey data that was stored on our computer server by the LimeSurvey application (through Excel) to SAS (SAS 9.1, Cary, NC). We uploaded the environmental data collected from the sensors. We then combined the data from the surveys and the indoor environmental monitors with the data on ambient ozone. Subjects were linked by the floor level of their workstation plus the completion date of each questionnaire to the relevant filter material and to measured indoor and outdoor environmental conditions. We analyzed all data using SAS, including the response rates over the five study periods and the level of six selected symptom outcomes. We performed initial descriptive, univariate analyses, then unadjusted bivariate analyses on the associations of symptoms with the filter material and other selected factors, and finally performed multivariate analyses. For the latter, we used SAS Proc Genmod with generalized estimating equations (GEE) to create models reflecting that data were collected repeatedly from each respondent over time.

We estimated the associations between each symptom outcome and filter material ( 2 types) and ambient ozone concentration (2 levels). Models included an "interaction" between filter material and ambient ozone (using the observed median level as a cut-off between low and high), thus allowing the estimated effects of filter material to differ at lower and higher ambient ozone levels. We planned to adjust the model for floor in building (5 levels), indoor temperature (measured continuously), indoor carbon dioxide as a proxy for ventilation rate (2 levels), and time of day of questionnaire completion (2 levels); however, one $\mathrm{CO}_{2}$ monitor failed, so this was omitted from the models.

For additional details of the statistical modeling approach, see Appendix 4.

\section{Results}

Attendance was extremely low at all three of the pre-study presentations that we conducted to inform workers about the upcoming study and to invite their participation in the survey: each session drew 2-4 people out of the hundreds of total occupants. We had provided text for email announcements about the presentation to Facilities staff to send out to managers of potential participants. Unbeknownst to us, the first presentation was not publicized because a notice was sent to only one manager to send out more broadly, but the manager was out of the office then and through the day of the meeting. For the second and third meetings, individual email 
messages were apparently sent out (i.e., not by us, but sent by Facilities staff to managers at the three tenant sub-agencies) to all eligible employees, but still almost no one attended the presentations. This was an early indication of the low level of involvement in the study by both managers and occupants.

We will refer to the three employee groups included in the study, all within the same federal agency, as groups B, S, and I. The I group was the only one for which communication conditions approximated those for which the survey was designed. We were given email addresses for all workers in that group who had workstations within either study space. We were thus able to contact all these workers (31) directly by email, ask them about their willingness to participate, remove from our email list all who chose not to participate, provide willing participants with unique personal links to the surveys through personal emails, and selectively recontact only the non-respondents with direct email reminders. Managers and other employees were not told who participated.

In group $\mathrm{S}$, the management decided (without our knowledge) to ask all employees directly (but without pressure) if they were willing to participate in the survey, and then provided us with the email addresses of the six (out of 18) employees who agreed. We were thus not able to communicate directly about the study with a large proportion of the workers in this group. Also, managers were aware of which workers agreed initially to participate, which was inappropriate.

In group B, the largest of the groups, we were not given email addresses of individual employees, but were required to send prototype emails to one environmental health and safety worker who forwarded them to all workers in the group. This included, for each study period, the initial invitation to participate and one additional reminder to complete the survey. We were not, however, able to get an exact count of potential workers in this group, although we received an unofficial estimate of about 150.

For all participants with whom we had direct email contact (all of group B and the subset of group I who had initially agreed to participate), we were able to follow the planned survey protocol. In group B, with no direct email access, even those who decided at any point not to participate still received all later emails related to the study. (For this group, the Human Subjects Committee suggested that we send out only one general reminder during each study session, as opposed to two carefully targeted reminders in the other groups). In this group, we also could not provide each participant's token electronically in email messages. Therefore, we printed out token numbers on individual sheets of paper, had these distributed in mailboxes of all potential participants (without being able to keep track of who actually received their token), and asked them to keep and use this token repeatedly over the 8-10 week study.

Starting on the second Wednesday of each 2-week study period, we emailed participants and asked them to complete the questionnaires in the afternoon on Wednesday, Thursday, or Friday of that week. Some surveys were nevertheless completed in the morning or not until the following week during a later study period. The result was that some respondents submitted no survey in some study periods but two surveys in other study periods; these were both accepted by the survey system because they were considered two different surveys, although submitted during one study period. We considered all surveys completed, during any work hour any day of 
the week, to be potentially eligible. However, we considered only the last of any multiple surveys submitted by each participant within each study period to be eligible, and we considered surveys completed during a "transition" day on which filters were changed to be ineligible.

\section{Response rates}

Table 2 shows response numbers by work group and by study floor. Calculation of exact response rates was possible only within the two work groups for which we had exact numbers for total employees. We were unable to obtain total employee counts for work group B, or for study floors.

Overall response was very low, and some of those among the submitted surveys were ineligible (not included in Table 2) due to multiple submission within a study period or submission on a transition day. The overall response was highest (34\%) in group I, for which we had complete email access and were able to follow the planned survey strategy; lower $(23 \%)$ in group S, to which we had email access to only one third of the total employees; and only a little lower than that $(21 \%)$ in group B, to which we had no direct email access. Overall, of approximately 995 potential questionnaires possible from 199 occupants over five surveys, we received only 228 valid questionnaires $(23 \%)$.

Table 2. Response rates for occupant survey

\begin{tabular}{|c|c|c|c|c|c|c|}
\hline & \multicolumn{3}{|c|}{ Employee Group } & \multicolumn{2}{|c|}{ Study Group } & \multirow[t]{2}{*}{ Total } \\
\hline & B & S & I & Floor 1 & Floor 2 & \\
\hline & $\begin{array}{c}\text { (no } \\
\text { direct } \\
\text { email) }\end{array}$ & $\begin{array}{l}\text { (only } 6 \\
\text { initially } \\
\text { provided } \\
\text { emails) }\end{array}$ & $\begin{array}{c}\text { (all emails } \\
\text { provided) }\end{array}$ & & & \\
\hline $\begin{array}{l}\text { Total n of } \\
\text { eligible } \\
\text { workers }\end{array}$ & $\sim 150$ & 18 & 31 & ---" & ---" & ---" \\
\hline $\begin{array}{l}\text { Responses } \\
\text { by period }\end{array}$ & $\begin{array}{l}\text { percent } \\
\text { (n) }\end{array}$ & $\begin{array}{l}\text { percent } \\
\text { (n) }\end{array}$ & $\begin{array}{l}\text { percent } \\
\text { (n) }\end{array}$ & (n) & (n) & \\
\hline period 1 & $7(10)$ & $28(5)$ & $26(8)$ & $(10)$ & $(13)$ & $(23)$ \\
\hline period 2 & $31(46)$ & $17(3)$ & $29(9)$ & (16) & $(42)$ & $(58)$ \\
\hline period 3 & $24(36)$ & $17(3)$ & $16(5)$ & (13) & (31) & (44) \\
\hline period 4 & $24(36)$ & $28(5)$ & $48(15)$ & (13) & (43) & $(56)$ \\
\hline period 5 & $18(27)$ & $28(5)$ & $48(15)$ & $(10)$ & $(37)$ & $(47)$ \\
\hline $\begin{array}{l}\text { Total } \\
\text { responses }\end{array}$ & $21(155)$ & $23(21)$ & $34(52)$ & $(92)$ & $(166)$ & $(228)$ \\
\hline $\begin{array}{l}\text { Total } \\
\text { potential } \\
\text { responses }\end{array}$ & $(750)$ & $(90)$ & $(155)$ & & & \\
\hline
\end{tabular}

* total eligible workers on each study floor unknown, so percent response not reported 
Survey participation in each worker group had an initial peak during one of the first two periods, then stayed the same or declined into the third period. At this point, we scheduled a new fifth period, made a major effort to increase response in the remaining periods 4 and 5 (through emails to accessible occupants describing the low response rate to date, and requests to the management to support the study more strongly). This was somewhat successful in groups to which we had direct access, as response for periods 4 and 5 increased in groups I and S. Success in group B, with no direct email access, was limited.

Before these last two study periods, we also explored the possibility of providing financial incentives to potential participants to complete the last two questionnaires, in the form of a $\$ 25$ "e-gift-card" to a major retailer. These have been found to be effective incentives in prior studies. We received Human Subjects Committee approval, but ran into two other insurmountable problems - the federal agency occupying the study building would not allow us to pay for incentives with federal funds (which were supporting the pilot study), and some work group managers would not allow the incentives for various reasons (e.g., workers in non-study spaces in the building might be unhappy if not offered this incentive; the incentive would pay workers for time at work for which they were already being paid).

Results of environmental parameters monitored are provided in Table 3. Temperatures indoors showed little variation, less than $2^{\circ} \mathrm{F}$, and while slightly warm were mostly within the thermal comfort range. On the one floor for which we had valid $\mathrm{CO}_{2}$ data, these values were very low and showed little variation (the maximum was perhaps only $113 \mathrm{ppm}$ above outside levels), suggesting a consistently high ventilation rate on that floor. Outdoor ozone varied substantially over the five study periods.

Table 3. Environmental data - descriptive summary

\begin{tabular}{|c|c|c|c|}
\hline Percentile & $\begin{array}{c}\text { Indoor } \\
\text { Temperature, } \\
\text { (weekly work } \\
\text { hour mean, }{ }^{\mathbf{0}} \mathbf{F} \text { ) }\end{array}$ & $\begin{array}{c}\text { Indoor Carbon } \\
\text { Dioxide (weekly } \\
\text { work hour } \\
\text { mean, ppm)* }\end{array}$ & $\begin{array}{c}\text { Outdoor Ozone, } \\
\text { (daily mean, } \\
\text { ppb) }\end{array}$ \\
\hline Minimum & 74.0 & 394 & 24.0 \\
\hline 25 th & 74.3 & 515 & 42.4 \\
\hline $50^{\text {th }}$ (median) & 74.5 & 554 & 57.8 \\
\hline 75 th & 75.2 & 590 & 68.6 \\
\hline Maximum & 75.9 & 730 & 87.0 \\
\hline \multirow{2}{*}{ * floor 2 only }
\end{tabular}

The filter schedule for the study is shown in Table 4. Also shown are the values of measured environmental parameters by floor and study period. Temperature differences between floors were small, both overall $\left(0.26^{\circ} \mathrm{F}\right)$, and for specific weeks (range of differences, $0.10-0.86{ }^{\circ} \mathrm{F}$ ). Difference in $\mathrm{CO}_{2}$ (ventilation rate) could not be estimated. Ambient ozone concentrations showed the expected gradual reduction for the late summer/early autumn in Sacramento. 
Table 4. Filter schedule and measured environmental parameters, by study period

\begin{tabular}{|c|c|c|c|c|c|c|c|c|c|}
\hline \multirow[t]{2}{*}{$\begin{array}{l}\text { Study } \\
\text { Period }\end{array}$} & \multirow[t]{2}{*}{$\begin{array}{l}\text { Planned } \\
\text { Filter } \\
\text { Change } \\
\text { Dates }\end{array}$} & \multirow[t]{2}{*}{$\begin{array}{c}\text { Survey } \\
\text { Dates }\end{array}$} & \multicolumn{2}{|c|}{$\begin{array}{c}\text { Filter } \\
\text { conditions** }\end{array}$} & \multicolumn{2}{|c|}{$\begin{array}{c}\text { Indoor } \\
\text { Temperature } \\
\text { (work hour } \\
\text { mean, }{ }^{\circ} \text { F) }\end{array}$} & \multicolumn{2}{|c|}{$\begin{array}{c}\text { Indoor } \\
\text { Carbon } \\
\text { Dioxide, } \\
\text { (work hour } \\
\text { mean, ppm) }\end{array}$} & \multirow{2}{*}{$\begin{array}{c}\text { Outdoor } \\
\text { Ozone } \\
\text { (ppb) }\end{array}$} \\
\hline & & & $\begin{array}{c}\text { Floor } \\
1\end{array}$ & $\begin{array}{c}\text { Floor } \\
2\end{array}$ & $\begin{array}{c}\text { Floor } \\
1\end{array}$ & $\begin{array}{c}\text { Floor } \\
2\end{array}$ & $\begin{array}{c}\text { Floor } \\
1 *\end{array}$ & $\begin{array}{c}\text { Floor } \\
2\end{array}$ & \\
\hline 1 & Aug 4 & Aug 13-15 & $\mathrm{S}$ & $\mathrm{F}$ & 75.6 & 75.8 & -- & 553 & 77.2 \\
\hline 2 & Aug 18 & Aug 27-29 & $\mathrm{F}$ & $\mathrm{S}$ & 74.4 & 75.3 & -- & 530 & 58.4 \\
\hline 3 & Sept 1 & Sep 10-12 & $\mathrm{S}$ & $\mathrm{F}$ & 74.4 & 74.5 & -- & 557 & 66.1 \\
\hline 4 & Sep 15 & Sep 24-26 & $\mathrm{F}$ & $\mathrm{S}$ & 74.3 & 74.7 & -- & 574 & 58.8 \\
\hline 5 & Sep 29 & Oct $8-10$ & $\mathrm{~S}$ & $\mathrm{~F}$ & 74.0 & 74.2 & -- & 577 & 38.0 \\
\hline $\begin{array}{l}\text { Study } \\
\text { Mean }\end{array}$ & & & & & 74.5 & 74.8 & -- & 558 & 57.7 \\
\hline
\end{tabular}

Table 5 shows the distributions of reported symptom severities for each period and study floor. For each symptom, a large proportions of respondents reported 0 severity (no symptom at all), with proportions over $50 \%$ for lower respiratory symptoms, skin symptoms, headache, and fatigue; $43 \%$ for eye symptoms, and $32 \%$ for upper respiratory symptoms. This is important because some statistical models (see Appendix 4) have limits on the proportion of 0 values in outcome data (no more than about $40 \%$ ) that can be used.

Table 5. Frequency of severity for symptoms

\begin{tabular}{|c|c|c|c|c|c|c|}
\hline \multicolumn{7}{|c|}{ Symptom Frequency } \\
\hline $\begin{array}{l}\text { Symptom } \\
\text { Severity }\end{array}$ & $\begin{array}{c}\text { Upper } \\
\text { Respiratory } \\
\mathrm{n}(\%)\end{array}$ & $\begin{array}{c}\text { Lower } \\
\text { Respiratory } \\
\mathrm{n}(\%)\end{array}$ & $\begin{array}{l}\text { Eyes } \\
\text { n }(\%)\end{array}$ & $\begin{array}{l}\text { Skin } \\
\mathrm{n}(\%)\end{array}$ & $\begin{array}{c}\text { Headache } \\
\mathrm{n}(\%)\end{array}$ & $\begin{array}{c}\text { Fatigue } \\
\text { n (\%) }\end{array}$ \\
\hline 0 & $\begin{array}{c}74 \\
(32 \%) \\
\end{array}$ & $\begin{array}{c}158 \\
(70 \%) \\
\end{array}$ & $\begin{array}{c}100 \\
(44 \%)\end{array}$ & $\begin{array}{c}138 \\
(61 \%)\end{array}$ & $\begin{array}{c}137 \\
(60 \%)\end{array}$ & $\begin{array}{c}120 \\
(53 \%)\end{array}$ \\
\hline 0.33 & 15 & 11 & & & & \\
\hline 0.67 & 24 & 14 & & & & \\
\hline 1 & 13 & 7 & 22 & 22 & 17 & 18 \\
\hline 1.33 & 9 & 7 & & & & \\
\hline 1.67 & 9 & 3 & & & & \\
\hline 2 & 12 & 3 & 19 & 21 & 15 & 11 \\
\hline
\end{tabular}




\begin{tabular}{|c|c|c|c|c|c|c|}
\cline { 4 - 7 } 2.33 & 12 & 4 & & & & \\
\hline 2.67 & 7 & 4 & & & & \\
\hline 3 & 8 & 1 & 16 & 9 & 8 & 7 \\
\hline 3.33 & 4 & 4 & & & & \\
\hline 3.67 & 6 & 0 & & & & 7 \\
\hline 4 & 2 & 2 & 4 & 11 & 6 & \\
\hline 4.33 & 1 & 0 & & & & 11 \\
\hline 4.67 & 1 & 3 & & & & \\
\hline 5 & 6 & 0 & 15 & 7 & & \\
\hline 5.33 & 5 & 0 & & & & \\
\hline 5.67 & 3 & 0 & & & & \\
\hline 6 & 1 & 1 & 18 & 6 & & \\
\hline 6.33 & 3 & 0 & & & & \\
\hline 6.67 & 6 & 0 & & & & \\
\hline 7 & 1 & 0 & 18 & 3 & & \\
\hline 7.33 & 0 & 1 & & & & \\
\hline 7.67 & 1 & 0 & & & & \\
\hline 8 & 2 & 0 & 10 & 5 & 5 & 14 \\
\hline 9 & 1 & 1 & 4 & 2 & 0 & 3 \\
\hline 9.33 & 0 & 1 & & & & \\
\hline 9.67 & 0 & 0 & & & & \\
\hline 10 & 1 & 1 & 1 & 227 & & \\
\hline Total & 227 & 226 & 227 & 226 & 227 & \\
\hline
\end{tabular}

The distributions of average symptom severity by floor and study period, for the six symptoms used in analyses, are provided in Table 6a. Symptoms were generally highest during the first study period, with few exceptions, but did not show consistent reductions afterwards. Symptom severities were also almost always higher on floor 2 than on floor 1, except for headache and upper respiratory symptoms.

Symptom severities by filter type and study periods are shown in Table $6 \mathrm{~b}$, with two sets of summary numbers. Because the symptoms are highest in period 1 in all groups, and floor 2 has a much larger set of responses, this may limit the effectiveness of the crossover design in compensating weekly differences, and increase the apparent negative influence of the filter used on floor 2 in period 1 (i.e., the fiberglass filter). For this reason we have also provided the summary means excluding period 1 . Means for all periods showed at least some greater severity of all symptoms for fiberglass filters. Means for periods 2-5 showed a less consistent pattern, with fiberglass filters associated with more severe symptoms for four of six symptoms. 
Table 6a. - Average symptom severity by floor and study period

\begin{tabular}{|c|c|c|c|c|c|c|c|c|c|c|c|c|}
\hline & \multicolumn{12}{|c|}{ Symptoms* } \\
\hline & \multirow{2}{*}{\multicolumn{2}{|c|}{$\begin{array}{c}\begin{array}{c}\text { Upper } \\
\text { Respiratory }\end{array} \\
\text { floor } \\
\end{array}$}} & \multirow{2}{*}{\multicolumn{2}{|c|}{$\begin{array}{c}\begin{array}{c}\text { Lower } \\
\text { Respiratory }\end{array} \\
\text { floor } \\
\end{array}$}} & \multicolumn{2}{|c|}{ Eyes } & \multicolumn{2}{|c|}{ Skin } & \multicolumn{2}{|c|}{ Headache } & \multicolumn{2}{|c|}{ Fatigue } \\
\hline & & & & & & & & & & & & \\
\hline $\begin{array}{l}\text { Study } \\
\text { period }\end{array}$ & 1 & 2 & 1 & 2 & 1 & 2 & 1 & 2 & 1 & 2 & 1 & 2 \\
\hline 1 & 2.30 & 2.15 & 0.90 & 1.44 & 2.50 & 3.15 & 1.33 & 2.62 & 2.20 & 1.69 & 2.20 & 3.31 \\
\hline 2 & 1.35 & 1.66 & 0.38 & 0.60 & 1.25 & 2.74 & 1.31 & 1.60 & 1.19 & 1.60 & 1.56 & 2.20 \\
\hline 3 & 0.72 & 2.85 & 0.28 & 0.62 & 1.15 & 3.26 & 0.54 & 1.48 & 0.69 & 2.10 & 0.92 & 2.58 \\
\hline 4 & 1.41 & 1.56 & 0.51 & 0.71 & 1.62 & 2.48 & 0.62 & 1.17 & 2.00 & 1.90 & 2.15 & 2.73 \\
\hline 5 & 1.27 & 1.62 & 0.13 & 0.59 & 2.10 & 2.59 & 1.00 & 1.38 & 2.00 & 1.51 & 1.50 & 2.03 \\
\hline Overall & 1.37 & 1.89 & 0.43 & 0.69 & 1.65 & 2.77 & 0.95 & 1.50 & 1.55 & 1.76 & 1.65 & 2.45 \\
\hline
\end{tabular}

* Mean values for symptoms on a scale from $0-10$

Table 6b. - Average symptom severity by filter type and study period

\begin{tabular}{|c|c|c|c|c|c|c|c|c|c|c|c|c|}
\hline & \multicolumn{12}{|c|}{ Symptoms* } \\
\hline & \multirow{2}{*}{\multicolumn{2}{|c|}{$\begin{array}{c}\begin{array}{c}\text { Upper } \\
\text { Respiratory }\end{array} \\
\text { Filter type } \\
\end{array}$}} & \multirow{2}{*}{\multicolumn{2}{|c|}{$\begin{array}{c}\begin{array}{c}\text { Lower } \\
\text { Respiratory }\end{array} \\
\text { Filter type }\end{array}$}} & \multicolumn{2}{|c|}{ Eyes } & \multicolumn{2}{|c|}{ Skin } & \multicolumn{2}{|c|}{ Headache } & \multicolumn{2}{|c|}{ Fatigue } \\
\hline & & & & & Filt & type & Filte & type & Filte & type & Filte & type \\
\hline $\begin{array}{l}\text { Study } \\
\text { period }\end{array}$ & $\mathrm{S}$ & $\mathrm{F}$ & $\mathrm{S}$ & $\mathrm{F}$ & $\mathrm{S}$ & $\mathrm{F}$ & $\mathrm{S}$ & $\mathrm{F}$ & $\mathrm{S}$ & $\mathrm{F}$ & $\mathrm{S}$ & $\mathrm{F}$ \\
\hline 1 & 2.30 & 2.15 & 0.90 & 1.44 & 2.50 & 3.15 & 1.33 & 2.62 & 2.20 & 1.69 & 2.20 & 3.31 \\
\hline 2 & 1.66 & 1.35 & 0.60 & 0.38 & 2.74 & 1.25 & 1.60 & 1.31 & 1.60 & 1.19 & 2.20 & 1.56 \\
\hline 3 & 0.72 & 2.85 & 0.28 & 0.62 & 1.15 & 3.26 & 0.54 & 1.48 & 0.69 & 2.10 & 0.92 & 2.58 \\
\hline 4 & 1.56 & 1.41 & 0.71 & 0.51 & 2.48 & 1.62 & 1.17 & 0.62 & 1.90 & 2.00 & 2.73 & 2.15 \\
\hline 5 & 1.27 & 1.62 & 0.13 & 0.59 & 2.10 & 2.59 & 1.00 & 1.38 & 2.00 & 1.51 & 1.50 & 2.03 \\
\hline $\begin{array}{c}\text { Mean, } \\
\text { all periods }\end{array}$ & 1.54 & 1.97 & 0.59 & 0.66 & 2.39 & 2.54 & 1.25 & 1.45 & 1.69 & 1.71 & 2.18 & 2.28 \\
\hline $\begin{array}{c}\text { Mean, } \\
\text { periods 2-5 }\end{array}$ & 1.47 & 1.94 & 0.56 & 0.55 & 2.38 & 2.45 & 1.24 & 1.30 & 1.64 & 1.71 & 2.18 & 2.14 \\
\hline $\begin{array}{l}\text { Ratio of } \\
\text { severity, } \\
\text { S vs. F } \\
\text { (per. 2-5) }\end{array}$ & 0.76 & & 1.02 & & 0.97 & & 0.92 & & 1.24 & & 1.02 & \\
\hline
\end{tabular}

$*$ Mean values for symptoms on a scale from $0-10$

Table 7 provides results of bivariate analyses of symptom severity with other independent variables, one at a time, including filter material, ambient ozone, indoor temperature, and time of 
day of questionnaire completion. Symptom severities overall were highest for eye symptoms and fatigue, intermediate for upper respiratory symptoms, headache, and skin symptoms, and very low for lower respiratory symptoms. Severity of all symptoms was slightly higher with fiberglass than with synthetic filters. Severity was increased with higher ozone for all symptoms except headache. Severity for most symptoms was higher for questionnaires completed in the morning, except for eye symptoms and fatigue. Severity of most symptoms was higher at higher indoor temperatures, except for headache and fatigue.

Table 7. Symptom severities - descriptive and bivariate analyses

\begin{tabular}{|c|c|c|c|c|c|c|}
\hline Independent & & & Sympto & & & \\
\hline & $\begin{array}{c}\text { Upper } \\
\text { Respiratory }\end{array}$ & $\begin{array}{c}\text { Lower } \\
\text { Respiratory }\end{array}$ & Eyes & Skin & Headache & Fatigue \\
\hline Overall & 1.75 & 0.62 & 2.46 & 1.35 & 1.70 & 2.23 \\
\hline $\begin{array}{l}\text { Filter } \\
\text { fiberglass } \\
\text { synthetic }\end{array}$ & $\begin{array}{l}1.97 \\
1.54\end{array}$ & $\begin{array}{l}0.66 \\
0.59\end{array}$ & $\begin{array}{l}2.54 \\
2.39\end{array}$ & $\begin{array}{l}1.45 \\
1.25\end{array}$ & $\begin{array}{l}1.71 \\
1.69\end{array}$ & $\begin{array}{l}2.28 \\
2.18\end{array}$ \\
\hline $\begin{array}{l}\text { Ambient Ozone } \\
\qquad 57.8 \mathrm{ppb} \\
\quad \geq 57.8 \mathrm{ppb}\end{array}$ & $\begin{array}{l}1.54 \\
1.95\end{array}$ & $\begin{array}{l}0.60 \\
0.65\end{array}$ & $\begin{array}{l}2.42 \\
2.50\end{array}$ & $\begin{array}{l}1.32 \\
1.38\end{array}$ & $\begin{array}{l}1.77 \\
1.63\end{array}$ & $\begin{array}{l}2.12 \\
2.34\end{array}$ \\
\hline $\begin{array}{c}\text { Time of Day } \\
\text { Morning } \\
\text { Afternoon }\end{array}$ & $\begin{array}{l}1.84 \\
1.62\end{array}$ & $\begin{array}{l}0.64 \\
0.59\end{array}$ & $\begin{array}{l}2.44 \\
2.49\end{array}$ & $\begin{array}{l}1.42 \\
1.26\end{array}$ & $\begin{array}{l}1.95 \\
1.37\end{array}$ & $\begin{array}{l}2.12 \\
2.38\end{array}$ \\
\hline $\begin{array}{l}\text { Indoor Temp (deg } \\
\text { C) } \\
\quad<75.04^{\circ} \mathrm{F} \\
\quad \geq 75.04{ }^{\circ} \mathrm{F}\end{array}$ & $\begin{array}{l}1.72 \\
1.82\end{array}$ & $\begin{array}{l}0.57 \\
0.77\end{array}$ & $\begin{array}{l}2.41 \\
2.62\end{array}$ & $\begin{array}{l}1.26 \\
1.61\end{array}$ & $\begin{array}{l}1.81 \\
1.40\end{array}$ & $\begin{array}{l}2.25 \\
2.19\end{array}$ \\
\hline
\end{tabular}

Table 8 provides estimates from multivariate models, which control for potential confounding by various factors, for the two (of six) symptom outcomes with data suitable for modeling (i.e., with sufficiently small proportions of "0" responses). Results for synthetic filters only suggested a very slight, non-significant increase for both symptoms. For higher ambient ozone, the model showed a significant $64 \%$ increase in severity for upper respiratory symptoms and a smaller nonsignificant increase in eye symptoms. The combination of synthetic filters and higher ambient ozone was not associated with an increase greater than would have been predicted based on the independent estimates for each, because the (non-significant) estimates for the interaction term were 0.67 and 0.90 rather than larger than 1.0 . 
In alternate models (not shown) for the two symptoms, excluding the non-significant interaction terms for filter*ozone, results were generally similar. In the alternate models, a significant association was seen only for higher ambient ozone and severity of upper respiratory symptoms (with a 35\% increase), but the small non-significant increase for eye symptoms with ozone persisted. The filter material effects were still not significant for either symptom.

Table 8. Results of multivariate modeling using SAS Proc Genmod with GEE - adjusted associations of symptom severity with independent variables of primary interest

\begin{tabular}{|c|c|c|}
\hline \multirow{2}{*}{$\begin{array}{l}\text { Independent } \\
\text { Variables }\end{array}$} & \multicolumn{2}{|c|}{ Symptoms } \\
\hline & $\begin{array}{c}\text { Upper } \\
\text { Respiratory }\end{array}$ & Eyes \\
\hline & $\begin{array}{l}\text { estimate } \\
\text { (p-value) }\end{array}$ & $\begin{array}{l}\text { estimate } \\
\text { (p-value) }\end{array}$ \\
\hline $\begin{array}{l}\text { Filter material } \\
\text { synthetic vs. } \\
\text { fiberglass }\end{array}$ & $\begin{array}{c}1.04 \\
(0.86)\end{array}$ & $\begin{array}{c}1.06 \\
(0.6684)\end{array}$ \\
\hline $\begin{array}{l}\text { Ambient } \\
\text { Ozone } \\
\text { above vs. } \\
\leq 57.8 \mathrm{ppb}\end{array}$ & $\begin{array}{c}1.64^{*} \\
(0.009)\end{array}$ & $\begin{array}{c}1.10 \\
(0.49)\end{array}$ \\
\hline $\begin{array}{l}\text { Filter material } \\
\text { * ozone } \\
\text { (polyester plus } \\
\text { ozone above } \\
57.8 \mathrm{ppb} \text { ) } \\
\end{array}$ & $\begin{array}{c}0.67 \\
(0.17)\end{array}$ & $\begin{array}{c}0.90 \\
(0.63)\end{array}$ \\
\hline $\begin{array}{l}\text { Floor } \\
1 \text { vs. } 2 \\
\end{array}$ & $\begin{array}{c}0.95 \\
(0.87)\end{array}$ & $\begin{array}{c}0.72 \\
(0.25)\end{array}$ \\
\hline $\begin{array}{l}\text { Time of Day } \\
\text { afternoon vs. } \\
\text { morning }\end{array}$ & $\begin{array}{c}0.87 \\
(0.33)\end{array}$ & $\begin{array}{c}0.78 \\
(0.08)\end{array}$ \\
\hline $\begin{array}{l}\text { Indoor } \\
\text { Temperature } \\
\quad\left(\text { per }^{\circ} \mathrm{F}\right)\end{array}$ & $\begin{array}{c}0.96 \\
(0.81)\end{array}$ & $\begin{array}{c}0.94 \\
(0.61)\end{array}$ \\
\hline
\end{tabular}

\section{Discussion}

The primary goals of this project were to design and field-test a protocol for conducting indoor environmental intervention research in office buildings, including a web-based occupant survey for occupants, and to recommend revisions to make it suitable for application in future field intervention studies in single or multiple office buildings. 
The web survey worked well technically, for the potential and active participants for whom we had email addresses, in

- allowing easy communication,

- allowing restricted communication when needed with only desired subgroups, such as continuing participants or non-respondents;

- collecting data;

- allowing production of a clean data set exportable for analysis.

\section{Lessons from the pilot study}

Overall response rate to the survey was very low. The overall response was best $(34 \%)$ in group I, for which we had complete email access and were able to use the effective communication techniques built into the survey; lower $(23 \%)$ in group S, to which we had email access from the beginning to only one third of the total employees; and only a little lower than that $(21 \%)$ in group B, to which we had no direct email access. Overall, of a total of approximately 995 potential questionnaires over five surveys from 199 occupants, we received only 228 valid questionnaires, a $23 \%$ response.

Some of this low response ( $22 \%$ vs. $34 \%$ ) can be attributed to lack of direct email contact with all occupants of the study spaces. It will be important to study buildings in which complete sets of email addresses for all occupants in the study spaces can be obtained.

Most of the low response may be attributable to limited buy-in and support for the study by the employer and employee managers. This led to poor publicity, limited awareness, lack of interest, and thus the low response rate. Our initial contact with the building staff was through the Facilities Department, who handled all the initial communication. Future studies should involve early and direct communication with employers and employee mangers. Contacts with employee representatives (unions) where available may also be helpful. In general, having enthusiastic support and buy-in within the office workforce from at least one influential person in each work group (a "champion") helps to increase response. We note that we used essentially the same protocol in a much longer study in a different office building the same year, and obtained responses in the $70-80 \%$ range. This other study had strong buy-in and support from the employer, who communicated this to the workers - that it was appropriate and in fact desired for them to spend time at work to complete the surveys. Therefore, the low response rate in this pilot does not indicate problems inherent in the protocol itself, or the impossibility of successfully surveying modern office workers. Also, small financial incentives such as gift cards or lotteries may help increase response in future studies.

Aside from the low response rate, the overall population on the two study floors turned out to be rather small, so that even with a high response rate the numbers for analysis would have been small. It is important to verify in advance that adequate population sizes are available for the questions being asked. Also, obtaining accurate counts of employees in advance is important for calculating accurate response rates. 
The very different numbers of responses on the two study floors, and the much greater severity of symptoms on one floor, throughout the study, was surprising. This posed a challenge to the analysis, which depends on the crossover design, and balanced responses from the two study areas to adjust for differences between the two study groups as the experimental conditions alternate back and forth, and as symptom occurrence usually gradually declines irrespective of conditions. We were able to adjust for building floor in the model, although this is not usually done, and this seems to have solved the problem. No revision of the design in future studies seems to be needed for this issue.

Another problem with the survey was that some respondents did not understand when to complete the surveys. Some returned none in some weeks, and two in the following weeks; others completed the survey on a day when we were changing indoor conditions between study periods. While it would be simple to change the web-based survey system to prohibit submission of two surveys in one study period or submission during a transition day, this would not solve the underlying communication problem. This will require clearer explanation of when to complete the surveys - i.e., make clear when the current survey period ends, and that the next survey time will be two weeks later. There was a similar problem with time-of-day of survey completion. We asked for surveys to be completed in the afternoon, so that respondents would have some time at work to develop any health response. However, some respondents completed surveys in the morning. For this, we could set up the survey system to not allow access during the morning, and to provide a message asking the respondent to please wait until the afternoon.

One aspect of the data collected in this survey poses a problem for analyses that future studies must plan for. The survey asks about current severity of various symptoms, on a scale ranging from 0-10. Because of the numeric distribution of responses to these questions, only certain statistical models are appropriate for the analyses (see Appendix 4). However, the models we considered (Poisson and negative binomial) require that at least $40 \%$ of the answers are larger than 0 (given the average symptom severity between 1 and 3), and this was not the case for most of the symptoms included. Future studies may require prior exploration of suitable statistical approaches to handle this kind of data, if not the use of questions that produce a different kind of data. Some alternate approaches with the current type of survey question might include:

- logistic regression, either ordinal with data categorized data into $\sim 3$ levels, or regular with data dichotomized (avoids problems with distribution of outcome variables, but loses some information in the response scale).

- zero inflated Poisson, zero inflated negative binomial, or hurdle models with the unrevised data (if applicable, uses all information from outcome scale and allows multivariate adjustment; however, assumption of XIP/ZINB models that a subpopulation never reports symptoms may not be true -- but could include additional question for each symptom about whether the subjects ever have this symptom at work, to separate out a group of those who never experience the symptom from those who sometimes do; the hurdle model may not have this limitation.)

- non-parametric repeated measures tests (no assumptions about distributions, so can use entire response scale without loss of information; however, has less power than parametric tests, cannot adjust for other covariates, and cannot estimate variability or confidence intervals 
It will be important in future intervention studies not to place excessive demands on Facilities staff in study buildings. Even though in this pilot study we planned from the beginning to have LBNL staff do all filter installation and filter switching, Facilities staff needed to let us into the building, escort us, give us access to secure locations, and accompany us in mechanical rooms during our activities there during each building visit. In the beginning, their assistance in our installing and changing filters took more time than they could reasonably provide. To correct this, we sent two LBNL staff instead of one for each filter exchange operation and started earlier in the day, and the Facilities staff left us to work with the filters and returned only when we were done. This resolved the problem. In future studies, careful advanced planning to avoid such problems would be advisable..

To summarize the suggested revisions in the study protocol for future use:

- Building selection criteria should included that managers will provide complete sets of email addresses for all occupants in the study spaces.

- Future studies need early and direct communication with employers and employee managers, in addition to facilities staff. Contacts with employee representatives (unions) where available may also be helpful. In general, having enthusiastic support and buy-in within the office workforce from one or more influential person in each work group (a "champion") helps to increase response.

- It should be made clearer to participants exactly when during each study period they need to complete the surveys

- Alternate statistical approaches, such as different models or tests, need to be selected to make the best use of the kind of data that the surveys produce.

- Careful planning to avoid over-burdening Facilities staff will be important.

Findings from the intervention study

Findings from analyses of data from the multiple crossover intervention were limited by the small size of the study combined with the unusually low response rate. The adjusted findings for filter material and ozone were in the same direction as predicted for both symptoms, and higher ambient ozone was significantly associated with more severe upper respiratory symptoms. No evidence of synergy between filters and ozone was evident. The one statistically significant finding, if confirmed in future studies, would suggest a 64\% increase in severity of upper respiratory symptoms with outdoor ozone concentrations above about $58 \mathrm{ppb}$. Ozone concentrations at this level occur during a substantial part of the warm season in Sacramento and other cities.

Findings here differed from those in a prior study (Buchanan et al., 2008), which found increase in some symptoms with synthetic filters, some increase with increased outdoor ozone, and a greater increase with the presence of both these factors than would have been expected from the increase for each alone. Possible explanations for this difference include:uncertainty about the exact filter materials associated with increased symptoms in the previous study (i.e., synthetic, polyester, etc.) due to inexact descriptions; possible causation of the increased symptoms in the prior study by an unmeasured factor associated with synthetic filters rather than the filter material itself; the lack of low ozone levels in this study corresponding to the lower ozone levels in the prior study (the median outdoor ozone levels in the prior study were closer to the 
minimum levels in this study); use of symptom severity questions on one day in this study, versus retrospective symptom frequency questions over the last month in the prior study; the shorter time frame for each filter condition in the pilot study (two weeks vs. months or more in the prior study); and small sample size of the pilot study; .

Findings from this pilot provide valuable information on the distribution of symptoms in an office population, which will help with estimation of sample size and power calculations for future studies using this questionnaire and protocol. Tables 5 and 6 provide the distributions of reported symptom severities for the set of symptoms considered for initial analyses here.

The pilot found significantly higher severity in upper respiratory symptoms when outdoor air ozone levels were above average, consistent with one major finding from a prior large multibuilding survey (Buchanan et al 2008) -- that prevalence of upper respiratory symptoms while working in office buildings increased linearly with increasing concentration of outdoor ozone. This finding agrees with findings by Buchanan et al. that ambient ozone exposures may influence health effects experienced indoors. These results indicate that technologies which reduce people's exposures to outdoor ozone can be, and should be, evaluated in future intervention studies. Parallel research that we performed in another section of the same study building has demonstrated that prefilters containing activated carbon can remove ozone for an extended period (Fisk et al. 2009). Prefilters containing activated carbon were removing $60 \%$ to $70 \%$ of the ozone at 67 and 81 days after filter installation, whereas the comparison filter bank without activated carbon removed negligible ozone This time period of effective ozone reduction is comparable to the usual time intervals for prefilter replacement, suggesting that effective ozone reduction could be accomplished in buildings with a change in filter specifications without requiring changes in maintenance practices or increased numbers of filters.

\section{Acknowledgments}

This research was supported by the U.S. General Services Administration (GSA) Public Buildings Service (contract number PX0008425) through an interagency agreement with the U.S. Department of Energy under Contract DE-AC02-05CH11231. The authors thank GSA Program manager Kevin Powell plus G. Allison, S. Blunder, K. Kampschroer, M. Levi, D. Marciniak, R. Odell, D. Triplett, and S. Ward, and also Doug Sullivan for assistance with study planning or implementation, and D. Lorenzetti and M. Sohn for reviewing a draft of this document.

\section{Appendices (see separate files)}

$\underline{\text { Appendix } 1}$ - Initial questionnaire

(See file GSA-filtint_App-1_qx-init.htm

with folder GSA-filtint_App-1_qx-init_files)

Appendix 2 - Recurring questionnaire 
(See file GSA-filtint_App-2_qx-recurrg.htm with folder GSA-filtint_App-2_qx-recurrg_files)

Appendix 3 - Pilot study protocol submitted to HSRB

(See file GSA-filtint_App-3_HumSubProt-fin.doc)

Appendix 4 - Details of the statistical modeling approach

(See file GSA-filt-int-study_App-4_stat.doc)

\section{References}

Buchanan, I. S. H, et al. (2008). "Air filter materials, outdoor ozone and building-related symptoms in the BASE study." Indoor Air 18(2): 144-155.

Fisk, W.J., Spears, M., Sullivan, D., and Mendell M.J. (2009) Ozone removal by filters containing activated carbon: a pilot study. To be presented at the Healthy Buildings 2009 Conference, September 13-17, 2009, Syracuse. NY. 


\section{GSA - Initial (Tokens)}

Initial Survey (revised 8/5/2008)

Consent Form

* $\mathrm{c}-1$ :

\section{The GSA/LBNL Healthy Building Study: \\ The Pilot Study at the Cottage Way Federal Building \\ COMPARISON OF TWO DIFFERENT KINDS OF PARTICLE FILTERS \\ IN VENTILATION SYSTEMS}

\section{PURPOSE AND BACKGROUND}

You are being asked to participate in a research study conducted by scientists at Lawrence Berkeley Nationa Laboratory: Mark Mendell, Ph.D. and William Fisk, M.S.

The major goal of this pilot study is to determine whether using air filters made from different materials mal a difference in any symptoms you might experience at work. It is part of a larger study with the goal of learn how to make office environments healthier and more comfortable for office workers.

This is a small pilot study, which is designed in part to test out the procedures we would use in a larger study We will try to learn from this study whether people understand the questionnaire, whether they fill out the questionnaire periodically as requested during the study, and how large a study needs to be in order to see a clear difference between study conditions.

\section{PROCEDURES}

This pilot study is comparing different kinds of filters in the building's ventilation systems. All ventilation systems contain filters that remove particles from the air that they bring into the building and circulate. The pilot study in your building will compare two types of filter - synthetic and fiberglass. One of the goals of this pilot study is to show whether either kind of filter provides measurable benefits to the health and environmer satisfaction of the occupants. We don't really know what the answer is yet, although the little bit of available research suggests that we may see a benefit with one kind.

The two floors in the East Wing of this building will be included in the study. The study will take place over eight weeks. During the study, the ventilation systems on each floor will always have different kinds of filters the two kinds we are comparing. For two weeks at a time, the ventilation system on your floor will use one ki of filter (either fiberglass or synthetic), while the other floor will use the other kind. Then every two weeks th filters will be switched. By the end of the eight- week study your space will have used the fiberglass filter for two-week periods and the synthetic filter for two, two-week periods.

You will receive emails every two weeks inviting you to participate in this survey, and providing you with a li to an electronic survey. Each survey will ask you to describe your health and experience at work at the time are filling it out. Each survey is expected to take no more than five minutes to complete. The first survey you complete will also ask you to answer some questions about yourself, such as about your gender and age, whet you have asthma or allergies, what level of education you have, and what kind of job you do. You may choose to answer any question at any time.

The types of filters used during this study are normal, commercially available filters used in many office buildings in this country and worldwide. If you have any concerns or questions, please contact us (see below section on "Questions").

\section{RISKS/DISCOMFORTS}

A small proportion of people in all office buildings always report experiencing minor health symptoms relate working in their buildings, although the causes of these symptoms have not been explained. An earlier study showed the amounts of symptoms were different among occupants in offices using different kinds of particle 
filters in the ventilation system - fiberglass or synthetic filters. So your overall experience of these minor symptoms may vary during the pilot study, depending on the type of filter. All these symptoms are considerer be minor and short-term, and most people do not experience them at all.

\section{BENEFITS}

Participating in the study will be of limited direct benefit to you. You may experience a reduction in symptor at work while one kind of filter is being used in your work space, if it turns out that symptoms are less commı with that filter. The results of the study will provide information on how best to filter air to office spaces, whi may benefit others in the future.

\section{STORAGE OF SAMPLES/DATA}

Survey responses will be stored in electronic data files available only to trained study staff.

\section{FINANCIAL CONSIDERATIONS}

The study will be of no cost to you. You will not be compensated for participating.

\section{QUESTIONS}

Any further questions you have about taking part in this study will be answered by Mark Mendell at (510) 486-5762 or (866) 562-4571 (toll free) or at mjmendell@lbl.gov.

Any questions you have about your rights as a study participant will be answered by the Berkeley Lab Hum Subjects Quality Assurance Committee at (510-486-5507).

\section{PARTICIPATION IN RESEARCH IS VOLUNTARY.}

You have the right to not take part in this survey, or to stop taking part at any time. You are under no obligation to disclose your participation or your decision not to participate to anyone, including your supervisor. We will not disclose to others at work, including other workers, your supervisor, or your employ whether or not you have participated, either during or after the study. Study findings reported after the conclusion of the study will contain no individual identifiers of participants. (Note: Others may learn of your participation; for instance, it is possible that management may review your e-mail or internet usage. Your management has approved our conduct of this study, and participation of their staff, but is not allowed to require your participation.)

[Click here to download a copy of this consent form, which you can save to your computer and print at anyti

\section{AUTHORIZATION}

To participate, please check the button below, next to "I agree," then click the button marked "next>>," anc the survey will begin. If you do not wish to participate, check the button next to that response, then click the button marked "next>>," and the next screen will let you submit your choice not to participate.

Please choose *only one* of the following:

I agree. I have read this consent form. All the questions I have about this study have been answere my satisfaction. I volunteer to participate in this survey research.

$\square$ I do not wish to participate in this survey.

[Only answer this question if you answered 'I agree. I have read this consent form. All the questions I have about th study have been answered to my satisfaction. I volunteer to participate in this survey research.' to question 'c-1 '] 
t-0: Thank you for agreeing to participate in this survey

\section{ALL YOUR ANSWERS WLL BE TREATED IN THE STRICTEST CONFDENCE.}

The survey will only be valid if you complete it at your workstation at work.

We would like you to answer all the questions. However, if you do not want to answer a question, choose "No answer" and then go on to the next question using the "next $>>$ " button.

To see previous screens while taking the survey, please use the "<< previous" button in the survey page, not y browser's Back button or Back arrow.

Please press the "next $>>$ " button below to continue.

1

YOUR JOB AND WORKPLACE

[Only answer this question if you answered 'I agree. I have read this consent form. All the questions I have about th study have been answered to my satisfaction. I volunteer to participate in this survey research.' to question 'c-1 ']

* 001: How long have you worked in the building where you work now?

Please choose *only one* of the following:

$\square$ Less than one year

$\square$ One or more years

No answer

[Only answer this question if you answered 'Less than one year' to question '001 ']

001.1: How many months have you worked in this building (round to the nearest month)?

Please write your answer here:

[Only answer this question if you answered 'One or more years' to question '001 ']

001.2: How many years (round to the nearest year)?

Please write your answer here:

\section{2}

YOUR JOB AND WORKPLACE

[Only answer this question if you answered 'I agree. I have read this consent form. All the questions I have about th study have been answered to my satisfaction. I volunteer to participate in this survey research.' to question 'c-1 ']

* 002: On average, how many hours each week do you work in this building?

Please choose *only one* of the following:

$\square 10$ hours or less

$\square$ 11-20 hours

$\square$ 21-40 hours

$\square$ More than 40 hours

$\square$ No answer 
[Only answer this question if you answered 'I agree. I have read this consent form. All the questions I have about th study have been answered to my satisfaction. I volunteer to participate in this survey research.' to question 'c-1 ']

* 003: Which best describes the space in which your current workstation is located?

\begin{tabular}{|c|}
\hline For this \\
que stionnaire, \\
your \\
"workstation" \\
is the place \\
(desk, \\
cubicle, \\
of fice, etc) \\
where you do \\
the majority \\
of your work \\
\hline
\end{tabular}

Please choose *nly one* of the following:

$\square$ Enclosed office, private

$\square$ Enclosed office, shared with other people

$\square$ Cubicles with partitions

$\square$ Workspace in open space with no partitions (just desks)

$\square$ Other

No answer

[Only answer this question if you answered 'Other' to question '003 ']

\section{1: Please specify "Other" workstation:}

Please write your answer here:

[Only answer this question if you answered 'Workspace in open space with no partitions (just desks)' or 'Other' or 'Cubicles with partitions' or 'Enclosed office, shared with other people' to question '003 ']

* 003.2: How many people work in the room in which your workstation is located (including yourself)?

Please choose *only one* of the following:
$2-3$
$\square$ 4-7
$\square 8$ or more
$\square$ No answer

\section{4}

YOUR JOB AND WORKPLACE

[Only answer this question if you answered 'I agree. I have read this consent form. All the questions I have about th study have been answered to my satisfaction. I volunteer to participate in this survey research.' to question 'c-1 ']

* 4-1: What floor of the building is your workstation on?

Please choose *only one* of the following:

$\square$ First

Second

No answer

[Only answer this question if you answered 'I agree. I have read this consent form. All the questions I have about th study have been answered to my satisfaction. I volunteer to participate in this survey research.' to question 'c-1 ']

* 4-2: What wing of the building are you in?

Please choose *only one* of the following:

East wing

West wing

No answer 
[Only answer this question if you answered 'I agree. I have read this consent form. All the questions I have about th study have been answered to my satisfaction. I volunteer to participate in this survey research.' to question 'c-1 ']

* 5-1: What best describes your job?

Please choose *all* that apply:

$\square$ Managerial

$\square$ Professional/Technical

$\square$ Secretarial or Clerical

$\square$ Other

$\square$ No answer

[Only answer this question if you answered 'Other' to question '5-1 ']

5-1a: Please specify "Other" job category:

Please write your answer here:

[Only answer this question if you answered 'I agree. I have read this consent form. All the questions I have about th study have been answered to my satisfaction. I volunteer to participate in this survey research.' to question 'c-1 ']

* 5-2: How many people at work do you supervise?

Please choose *only one* of the following:
$\square$ none
$\square 1$ to 4
$\square 5$ or more
No answer

\section{6}

YOUR JOB AND WORKPLACE

[Only answer this question if you answered 'I agree. I have read this consent form. All the questions I have about th study have been answered to my satisfaction. I volunteer to participate in this survey research.' to question 'c-1 ']

* 6-1: How stressful is your job?

Please choose only one response:

Please choose the appropriate response for each item:

$\begin{array}{cccccc}\text { not at all stressful } & 2 & 3 & 4 & 5 & 6 \\ \square & \square & \square & \square & \square & \square\end{array}$

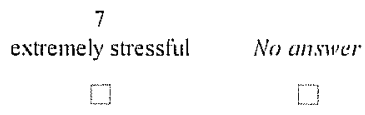

\section{7}

YOUR JOB AND WORKPLACE

[Only answer this question if you answered 'I agree. I have read this consent form. All the questions I have about th study have been answered to my satisfaction. I volunteer to participate in this survey research.' to question 'c-1 ']

* 7-1: All in all, how satisfied are you with your job?

Please choose only one response:

Please choose the appropriate response for each item:

$\begin{array}{cccccccc}1 & & & & 7 & \\ \text { very dissatisfied } & 2 & 3 & 4 & 5 & 6 & \text { very satisfied } & \text { No an.swe. } \\ \square & \square & \square & \square & \square & \square & \square & \square\end{array}$




\section{8}

YOUR WORK ENVIRONMENT

[Only answer this question if you answered 'I agree. I have read this consent form. All the questions I have about th study have been answered to my satisfaction. I volunteer to participate in this survey research.' to question 'c-1 ']

* 8-1: How would you rate the current temperature in your workspace?

Please choose only one response:

Please choose the appropriate response for each item:

$\begin{array}{cccc}1 & 2 & 3 & 4 \\ \begin{array}{c}\text { much too } \\ \text { cool }\end{array} & \text { too } & \text { comfortably } & \text { comfortable, neither warm nor } \\ \text { cool } & \text { cool } & \text { cool }\end{array}$

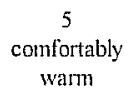$$
\begin{gathered}
6 \\
\text { too } \\
\text { warm }
\end{gathered}
$$$$
\begin{aligned}
& 7 \\
& \text { marm } \\
& \text { warm }
\end{aligned}
$$

[Only answer this question if you answered 'I agree. I have read this consent form. All the questions I have about th study have been answered to my satisfaction. I volunteer to participate in this survey research.' to question 'c-1 ']

* 8-2: How would you rate the current humidity in your workspace?

Please choose only one response:

Please choose the appropriate response for each item:

$\begin{array}{cccc}1 & 2 & 3 & 4 \\ \begin{array}{c}\text { much too } \\ \text { dry }\end{array} & \text { too } & \text { confortably } & \text { comfortable, neither dry nor } \\ \text { dry } & \text { dry } & \text { humid }\end{array}$

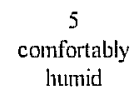

6
too
humid

7

much too

huminid

\section{9}

YOUR WORK ENVIRONMENT

[Only answer this question if you answered 'I agree. I have read this consent form. All the questions I have about th study have been answered to my satisfaction. I volunteer to participate in this survey research.' to question 'c-1 ']

* 9-1: How satisfied are you with the current air quality in your workspace, in terms of its freshness?

Please choose only one response:

Please choose the appropriate response for each item:

$\begin{array}{cccccccc}\begin{array}{c}1 \\ \text { very dissatisfied }\end{array} & 2 & 3 & 4 & 5 & 6 & \text { very satisfied } & \text { No answer } \\ \square & \square & \square & \square & \square & \square & \square & \square\end{array}$

\section{0}

YOUR WORK ENVIRONMENT

[Only answer this question if you answered 'I agree. I have read this consent form. All the questions I have about th study have been answered to my satisfaction. I volunteer to participate in this survey research.' to question 'c-1 ']

* 10-1: How satisfied are you with the current air quality in your workspace, in terms of odors?

Ple ase choose only one response:

Please choose the appropriate response for each item:

$\begin{array}{cccccccc}1 & & & & 7 & \\ \text { very dissatisfied } & 2 & 3 & 4 & 5 & 6 & \text { very satisfied } & \text { No answer } \\ \square & \square & \square & \square & \square & \square & \square & \square\end{array}$


[Only answer this question if you answered 'I agree. I have read this consent form. All the questions I have about th study have been answered to my satisfaction. I volunteer to participate in this survey research.' to question 'c-1 ']

* 11-1: Have you ever been told by a doctor that you had any of the following?

Please choose *all* that apply:

Asthma

$\square$ Eczema

$\square$ Hay fever/pollen allergy

$\square$ Allergy to dust mites or dust

Allergy to mold

$\square$ No, none of the above

$\square$ No answer

[Only answer this question if you answered 'Asthma' to question '11-1 ']

* 11-2: What year were you first diagnosed with asthma?

Please write your answer here:

\section{2}

Symptoms at Work Today (1)

The following questions ask about specific symptoms people may have.

For each symptom below, the row of circles represents the range of severity from none to very severe.

[Only answer this question if you answered 'I agree. I have read this consent form. All the questions I have about th study have been answered to my satisfaction. I volunteer to participate in this survey research.' to question 'c-1 ']

* 12-1: Please mark the circle that represents

how severe each symptom has been for you

at work TODAY:

Please choose the appropriate response for each item:

Please choose the appropriate response for each item:

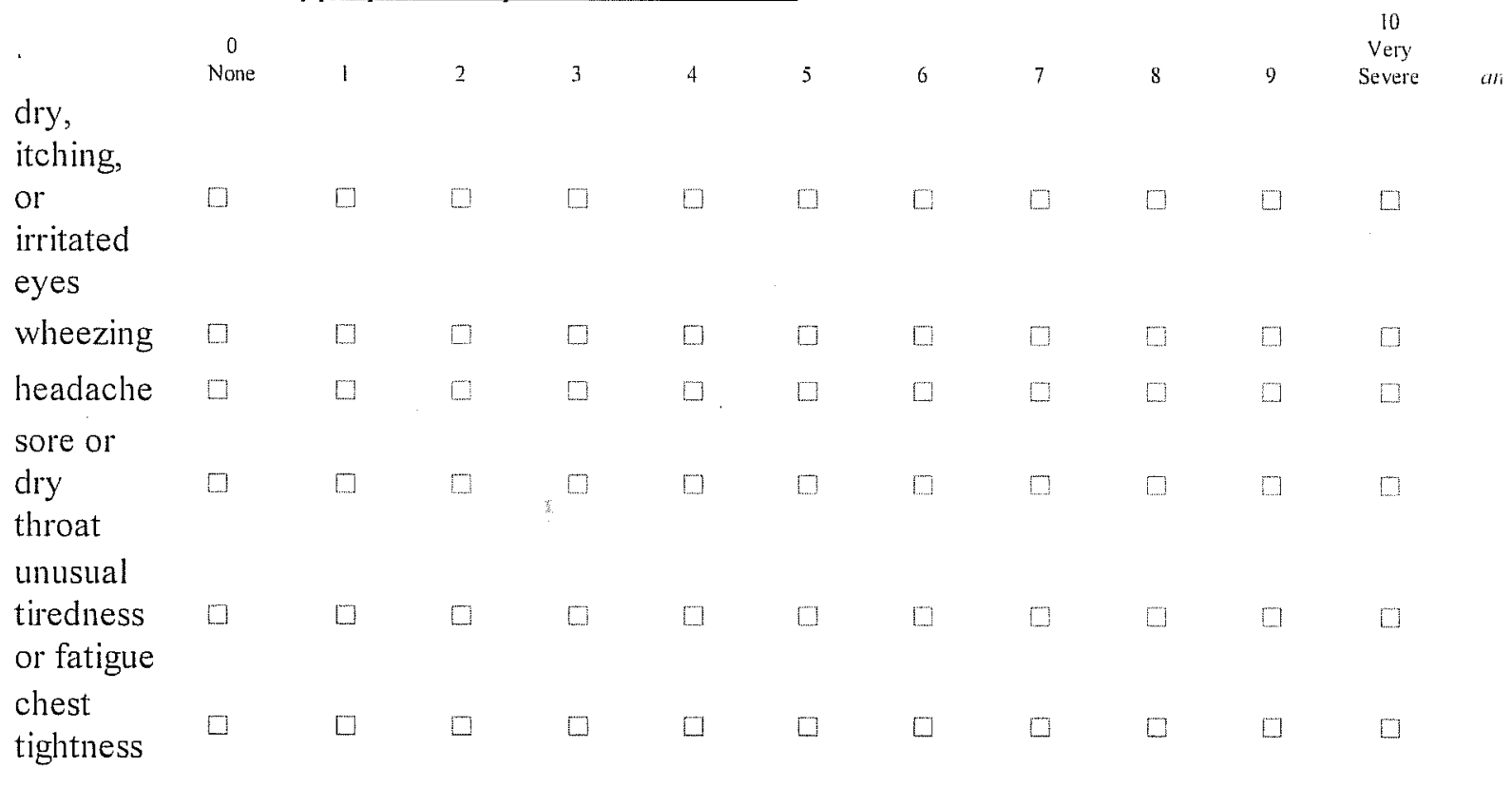




\section{3}

Symptoms at Work Today (2)

The following questions ask about specific symptoms people may have.

For each symptom below, the row of circles represents the range of severity from none to very severe.

[Only answer this question if you answered 'I agree. I have read this consent form. All the questions I have about th study have been answered to my satisfaction. I volunteer to participate in this survey research.' to question 'c-1 ']

* 13-1: Please mark the circle that represents

how severe each symptom has been for you at work TODAY:

Please choose the appropriate response for each item:

Please choose the appropriate response for each item:

\begin{tabular}{|c|c|c|c|c|c|c|c|c|c|c|c|}
\hline & $\begin{array}{c}0 \\
\text { None }\end{array}$ & 1 & 2 & 3 & 4 & 5 & 6 & 7 & 8 & 9 & $\begin{array}{c}10 \\
\text { Very } \\
\text { Severe }\end{array}$ \\
\hline $\begin{array}{l}\text { congested } \\
\text { nose }\end{array}$ & E] & 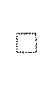 & $\square$ & $\square$ & $\square$ & $\square$ & $\square$ & $\square$ & $\square$ & $\square$ & 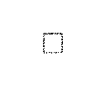 \\
\hline cough & $\square$ & $\square$ & $\square$ & $\square$ & $\square$ & $\square$ & $\square$ & $\square$ & $\square$ & [] & $\square$ \\
\hline sneezing & $\square$ & $\square$ & $\square$ & $\square$ & $\square$ & $\square$ & $\square$ & $\square$ & $\square$ & $\square$ & $\square$ \\
\hline $\begin{array}{l}\text { shortness } \\
\text { of breath }\end{array}$ & {[} & $\square$ & [ & $\square$ & $\square$ & Q & $\square$ & $\square$ & $\square$ & $\Gamma$ & $\square$ \\
\hline $\begin{array}{l}\text { dry or } \\
\text { itchy skin }\end{array}$ & $\square$ & $\square$ & $\square$ & $\square$ & $\square$ & $\square$ & $\square$ & $\square$ & $\square$ & $\square$ & $\square$ \\
\hline $\begin{array}{l}\text { muscle, } \\
\text { joint, or } \\
\text { back } \\
\text { pains }\end{array}$ & D & $\square$ & $\square$ & $\square$ & $\square$ & $\square$ & $\square$ & $\square$ & $\square$ & $\square$ & {[} \\
\hline
\end{tabular}

[Only answer this question if you answered 'I agree. I have read this consent form. All the questions I have about th study have been answered to my satisfaction. I volunteer to participate in this survey research.' to question 'c-1 ']

* 14-1: Do you have a respiratory illness today, such as a common cold or influenza (flu)?

Please choose *only one* of the following:

$\square$ Yes
No
No Answer

[Only answer this question if you answered 'I agree. I have read this consent form. All the questions I have about th study have been answered to my satisfaction. I volunteer to participate in this survey research.' to question 'c-1 '] * 14-2: In the last 4 work weeks including this week, on how many days were you absent from work for any reason? (Count only whole days, but if you missed more than half of a day count as one day.) Please report in whole days.

Please write your answer here:

[Only answer this question if you answered 'I agree. I have read this consent form. All the questions I have about th study have been answered to my satisfaction. I volunteer to participate in this survey research.' to question 'c-1 '] 
* 14-3: Now, of those times you were absent from work in the last 4 work weeks including this week - on how many of those days did you miss work because of health or illness problems or for health care? (Count only wh days, but count as one day if you missed more than half of a day -- because of health or illness problems or for health care.) Please report in whole days.

Please write your answer here:

\section{5}

[Only answer this question if you answered 'I agree. I have read this consent form. All the questions I have about th study have been answered to my satisfaction. I volunteer to participate in this survey research.' to question 'c-1 ']

* 15-1: Can you easily control any of the following that affect your workspace air environment?

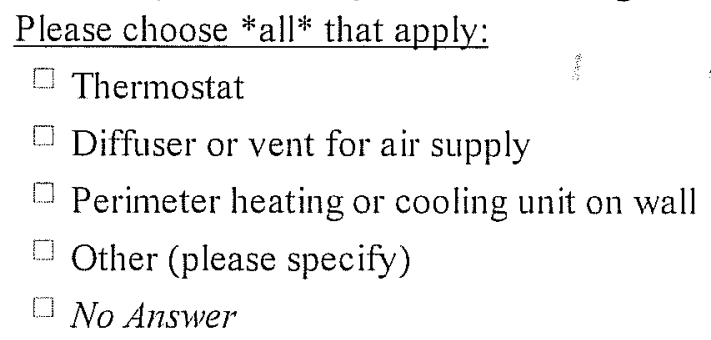

[Only answer this question if you answered 'I agree. I have read this consent form. All the questions I have about th study have been answered to my satisfaction. I volunteer to participate in this survey research.' to question 'c-1 'an, you answered 'Other (please specify)' to question '15-1']

15-1b: Please specify "Other" control method

Please write your answer here:

[Only answer this question if you answered 'I agree. I have read this consent form. All the questions I have about th study have been answered to my satisfaction. I volunteer to participate in this survey research.' to question 'c-1 ']

* 15-2: Have you self-modified your air delivery system for greater comfort?

Please choose *all* that apply:

Covered the air supply vent

Made air deflector for air supply vent

Other (please specify)

$\square$ No Answer

[Only answer this question if you answered 'I agree. I have read this consent form. All the questions I have about th study have been answered to my satisfaction. I volunteer to participate in this survey research.' to question 'c-1 ' $c$ n. you answered 'Other (please specify)' to question '15-2 ']

15-2b: Please specify "Other" modifications

Please write your answer here:

[Only answer this question if you answered 'I agree. I have read this consent form. All the questions I have about th study have been answered to my satisfaction. I volunteer to participate in this survey research.' to question 'c-1 ']

* 15-3: Do you have accessories in your workspace to help control the temperature?

Please choose *all* that apply:

Space heater

$\square$ Fan 
Other (please specify)

No Answer

[Only answer this question if you answered 'I agree. I have read this consent form. All the questions I have about th study have been answered to my satisfaction. I volunteer to participate in this survey research.' to question 'c-1 ' $a$, you answered 'Other (please specify)' to question '15-3 ']

15-3b: Please specify "Other" accessories

Please write your answer here:

\section{6}

[Only answer' this question if you answered 'I agree. I have read this consent form. All the questions I have about th study have been answered to my satisfaction. I volunteer to participate in this survey research.' to question 'c-1 ']

* 16-1: What is your tobacco smoking status?

Please choose *only one* of the following:

$\square$ Never smoked

Former smoker

Current smoker

No answer

\section{7}

[Only answer this question if you answered 'I agree. I have read this consent form. All the questions I have about th study have been answered to my satisfaction. I volunteer to participate in this survey research.' to question 'c-1 ']

* 17-1: How old were you on your last birthday?

Please choose *only one* of the following:

Under 20

20-29 years

$\square 30-39$ years

$40-49$ years

50-59 years

Over 59 years

$\square$ No answer.

18

[Only answer this question if you answered 'I agree. I have read this consent form. All the questions I have about th study have been answered to my satisfaction. [ volunteer to participate in this survey research.' to question 'c-1 ']

* 18-1: Are you:

Please choose *only one* of the following:

$\square$ Male

Female

$\square$ No answer

\section{9}

[Only answer this question if you answered 'I agree. I have read this consent form. All the questions I have about th study have been answered to my satisfaction. I volunteer to participate in this survey research.' to question 'c-1 '] 
* 19-1: What is the highest grade you completed in school?

Please choose * only one* of the following:

$\square$ Less than high school graduate

$\square$ High school graduate

C. Some college

College degree

$\square$ Graduate degree

$\square$ No answer

[Only answer this question if you answered 'I agree. I have read this consent form. All the questions I have about th study have been answered to my satisfaction. I volunteer to participate in this survey research.' to question 'c-1 '] 020: Please provide any other comments on the building environment or employee health.

Please write your answer here:

Submit Your Survey.

Thank you for completing this survey. Please fax your completed survey to: . 


\section{GSA - Recurring}

Repeated Survey (revised 8/5/2008)

1

YOUR JOB AND WORKPLACE

* 2-1: Since the last survey in this series, has the number of hours that you work in this building each week changed substantially?

Please choose *only one* of the following:

$\square$ Yes

$\square$ No

No Answer

[Only answer this question if you answered 'Yes' to question '2-1 ']

* 002: On average, how many hours each week do you work in this building?

Please choose *only one* of the following:

$\square 10$ hours or less

11-20 hours

21-40 hours

$\square$ More than 40 hours

No answer

\section{2}

YOUR JOB AND WORKPLACE

* 3-1a: Since the last survey in this series, has the Iocation of your workstation changed?

Please choose *only one* of the following:

$\square$ Yes

$\square$ No

No Answer

[Only answer this question if you answered 'Yes' to question '3-1a']

* 003: Which best describes the space in which your current worlstation is located?

\begin{tabular}{|c|}
\hline For this \\
questionnaire, \\
your \\
"workstation" \\
is the place \\
(desk, \\
cubicle, \\
office, etc) \\
where you do \\
the mijority \\
of your work. \\
\hline
\end{tabular}

Please choose *only one" of the following:

$\square$ Enclosed office, private

$\square$ Enclosed office, shared with other people

Cubicles with partitions

Workspace in open space with no partitions (just desks)

Other

No answer

[Only answer this question if you answered 'Other' to question '003 ' and if you answered 'Yes' to question '3-1a '] 003.1: Please specify "Other" workstation:

Please write your answer here:

[Only answer this question if you answered 'Other' or 'Workspace in open space with no partitions (just desks)' or 'Enclosed office, shared with other people' or 'Cubicles with partitions' to question '003 ' and if you answered 'Yes' to question '3-1a']

* 003.2: How many people work in the room in which your workstation is located (including yourself)? 
Please choose *only one* of the following:
$2-3$
$\square-7$
8 or more
$\square$ No answer

\section{3}

YOUR JOB AND WORKPLACE

[Only answer this question if you answered 'Yes' to question '3- la ']

* 4-1: What floor of the building is your workstation on?

Please choose *only one* of the following:

First

Second

No answer

[Only answer this question if you answered 'Yes' to question '3-1a ']

* 4-2: What wing of the building are you in?

Please choose *only one* of the following:

East wing

West wing

No answer

\section{4}

YOUR JOB AND WORKPLACE

* 5-1: How stressful is your job?

Please choose only one response:

Please choose the appropriate response for each item:

\begin{tabular}{cccccccc}
\hline not at all stressful & 2 & 3 & 4 & 5 & 6 & 7 \\
$\square$ & $\square$ & $\square$ & $\square$ & $\square$ & $\square$ & $\square$ & $\square$
\end{tabular}

\section{5}

YOUR JOB AND WORKPLACE

* 6-1: All in all, how satisfied are you with your job?

Please choose only one response:

Please choose the appropriate response for each item:

$\begin{array}{cccccccc}1 & & & & 7 \\ \text { very dissatisfied } & 2 & 3 & 4 & 5 & 6 & \text { very satisfied } & \text { Noranswer } \\ \square & \square & \square & \square & \square & \square & \square & \square\end{array}$

\section{6}

YOUR WORK ENVIRONMENT

* 7-1: How would you rate the current temperature in your workspace?

Please choose only one response:

Please choose the appropriate response for each item:

$\begin{array}{cccc}1 & 2 & 3 & 4 \\ \text { much too } & \text { to } & \text { comfortably } & \text { comfortable, neither warm no }\end{array}$




\begin{tabular}{|c|c|c|c|c|c|}
\hline cool & cool & cool & cool & warm & warm \\
\hline$\square$ & $\square$ & $\square$ & $\square$ & $\square$ & $\square$ \\
\hline
\end{tabular}

* 7-2: How would you rate the current humidity in your workspace?

Please choose the appropriate response for each item:

\begin{tabular}{|c|c|c|c|c|c|c|c|}
\hline $\begin{array}{l}1 \\
\text { imuch too } \\
\text { dry }\end{array}$ & $\begin{array}{l}2 \\
\text { too } \\
\text { dry }\end{array}$ & $\begin{array}{c}3 \\
\text { comfortably } \\
\text { dry }\end{array}$ & $\begin{array}{c}4 \\
\begin{array}{c}4 \\
\text { comfortable, neither dry nor } \\
\text { humid }\end{array}\end{array}$ & $\begin{array}{c}5 \\
\text { comfortably } \\
\text { huunid }\end{array}$ & $\begin{array}{c}6 \\
\text { too } \\
\text { lumid }\end{array}$ & $\begin{array}{c}7 \\
\text { much too } \\
\text { humid }\end{array}$ & $\begin{array}{c}\text { No } \\
\text { antwer }\end{array}$ \\
\hline$\Gamma$ & $\mathrm{D}$ & 0 & $\square$ & $\square$ & {[} & 0 & $\square$ \\
\hline
\end{tabular}

\section{YOUR WORK ENVIRONMENT}

* 8-1: How satisfied are you with the current air quality in your workspace, in terms of its freshness?

Plaase choose only one response:

Please choose the appropriate response for each item:

\begin{tabular}{ccccc|cccc} 
l & & & & & 7 \\
very dissatisfied & 2 & 3 & 4 & 5 & 6 & very satisfied & No answer \\
$\square$ & $\square$ & $\square$ & $\square$ & $\square$ & $\square$ & $\square$ & $\square$
\end{tabular}

\section{8}

YOUR WORK ENVIRONMENT

* 9-1: How satisfied are you with the current air quality in your workspace, in terms of odors?

Please choose only one response:

Please choose the appropriate response for each item:

$\begin{array}{cccccccc}\text { 1 } & & & & 7 \\ \text { very dissatisfied } & 2 & 3 & 4 & 5 & 6 & \text { very satisfied } & \text { No answer } \\ \square & \square & \square & \square & \square & \square & \square & \square\end{array}$

\section{9}

YOUR HEALTH AND WELL-BEING

* 10-1a: Since the last survey in this series, have you been told by a doctor that you had asthma, allergies, or eczema?

Please choose *only one* of the following:

$\square$ Yes

$\square$ No

No Answer

[Only answer this question if you answered 'Yes' to question ' 10-1a ']

* 10-1: Have you ever been told by a doctor that you had any of the following?

Please choose *all* that apply:

$\square$ Asthma

$\square$ Eczema

$\square$ Hay fever/pollen allergy

$\square$ Allergy to dust mites or dust

$\square$ Allergy to mold

$\square$ No, none of the above

$\square$ No answer 


\section{0}

Symptoms at Work Today (1)

The following questions ask about specific symptoms people may have.

For each symptom below, the row of circles represents the range of severity from none to very severe.

* 11-1: Please mark the circle that represents

how severe each symptom has been for you

at work TODAY:

Ple ase choose the appropriate response for each item:

Please choose the appropriate response for each item:

\begin{tabular}{|c|c|c|c|c|c|c|c|c|c|c|c|c|}
\hline & $\begin{array}{c}0 \\
\text { None }\end{array}$ & 1 & 2 & 3 & 4 & 5 & 6 & 7 & 8 & 9 & $\begin{array}{c}10 \\
\text { Very } \\
\text { Severe }\end{array}$ & $\begin{array}{c}\text { No } \\
\text { allsweren }\end{array}$ \\
\hline $\begin{array}{l}\text { dry, } \\
\text { itching, }\end{array}$ & & & & & & & & & & & & \\
\hline $\begin{array}{l}\text { or } \\
\text { irritated } \\
\text { eyes }\end{array}$ & $\mathrm{O}$ & $\square$ & $\square$ & $\square$ & $\square$ & $\mathrm{E}$ & $\square$ & $\square$ & $\square$ & $\square$ & $a$ & $\mathrm{E}$ \\
\hline wheezing & $\mathrm{D}$ & $\square$ & $\square$ & $\square$ & $\square$ & $\square$ & $\mathrm{D}$ & $\square$ & $\square$ & $\square$ & $\square$ & $\mathrm{T}$ \\
\hline headache & $\mathrm{T}$ & $\square$ & $\square$ & $\square$ & $\square$ & $\square$ & $\mathrm{D}$ & $\square$ & $\square$ & $\square$ & $\square$ & $\square$ \\
\hline $\begin{array}{l}\text { sore or } \\
\text { dry } \\
\text { throat }\end{array}$ & $\square$ & $\square$ & $\square$ & $\square$ & 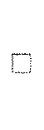 & $\square$ & $\square$ & $\square$ & $\square$ & $\square$ & $\square$ & $\square$ \\
\hline $\begin{array}{l}\text { unusual } \\
\text { tiredness } \\
\text { or fatigue }\end{array}$ & 0 & $W$ & 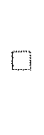 & 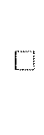 & $\square$ & $\square$ & 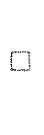 & $\square$ & $\square$ & $\square$ & $\square$ & $\square$ \\
\hline $\begin{array}{l}\text { chest } \\
\text { tightness }\end{array}$ & in & a & E] & $\square$ & $\square$ & $\square$ & $\square$ & $\square$ & $\square$ & $\square$ & $\mathrm{D}$ & m \\
\hline
\end{tabular}

\section{1}

Symptoms at Work Today (2)

The following questions ask about specific symptoms people may have.

For each symptom below, the row of circles represents the range of severity from none to very severe.

* 12-1: Please mark the circle that represents how severe each symptom has been for you at work TODAY:

Please choose the appropriate response for each ite m:

Please choose the appropriate response for each item: 
muscle,

joint, or

back

pains

\section{2}

* 13-1: Do you have a respiratory illness today, such as a common cold or influenza (flu)?

Please choose *only one* of the following:
$\square$ Yes
$\square$ No
No Answer

* 13-2: In the last 4 work weeks including this week, on how many days were you absent from work for any reason? (Count only whole days, but if you missed more than half of a day count as one day.) Please report in whole days.

Please write your answer here:

* 13-3: Now, of those times you were absent from work in the last 4 work weeks including this week - on how many of those days did you miss work because of health or illness problems or for health care? (Count only whole days, but count as one day if you missed more than half of a day -- because of health or illness problems or for health care.) Please report in whole days.

Please write your answer here:

\section{3}

* 15-1a: Since the last survey in this series, has your tobacco-smoking status changed?

Please choose *only one* of the following:

$\square$ Yes

$\square$ No

No Answer

[Only answer this question if you answered 'Yes' to question '15-1a ']

* 15-1: What is your tobacco smoking status?

Please choose *only one* of the following:

$\square$ Never smoked

Former smoker

$\square$ Current smoker

$\square$ No answer

\section{4}

019: Please provide any other comments on the building environment or employee health.

Please write your answer here: 
Submit Your Survey.

Thank you for completing this survey. Please fax your completed survey to: . 
